\title{
Induction of Antibodies Binding to the Membrane Proximal External Region of gp36 of HIV-2
}

\author{
R. Behrendt U. Fiebig R. Kurth J.Denner \\ Robert Koch Institute, Berlin, Germany
}

\section{Key Words}

HIV-2 $\cdot$ Vaccine $\cdot$ Neutralizing antibodies $\cdot$ Transmembrane envelope protein

\begin{abstract}
Objective: The ability to induce neutralizing antibodies may be the most important feature of an antiretroviral vaccine, preventing infection of target cells and subsequent integration of the virus into the cellular genome where the virus may persist. Broadly neutralizing antibodies directed against conserved epitopes in the membrane proximal external region (MPER) of the transmembrane envelope (TM) protein gp41 of HIV-1 such as the monoclonal antibodies (mAb) 2F5 and $m A b 4 E 10$ have been found in infected individuals; however, all attempts to induce such antibodies failed. In individuals infected with HIV-2 such antibodies were not yet reported. Methods: Two recombinant proteins corresponding to the ectodomain of the TM protein gp36 of HIV-2 were produced, rats were immunized and sera were analyzed for binding and neutralizing antibodies. Results: Although binding antibodies were induced, none of the sera neutralized HIV-2. Most interestingly, epitope mapping showed specific binding of the antibodies to the MPER of gp36, to a region homologous to the binding site of the $m A b 4 E 10$ in gp41 of HIV-1. Conclusions: Although MPER-specific anti-
\end{abstract}

bodies were induced by vaccination with gp36, these antibodies did not neutralize HIV-2. This is similar to the situation with HIV-1, but in contrast to that with gammaretroviruses.

Copyright $\odot 2011$ S. Karger AG, Basel

Broadly neutralizing antibodies, recognizing epitopes in the membrane proximal external region (MPER) of the transmembrane envelope (TM) protein gp41 of HIV-1, such as the monoclonal antibodies (mAb) 2F5 and $\mathrm{mAb}$ $4 \mathrm{E} 10$ have been isolated from HIV-1 infected individuals [1-3]. mAb 2F5 and mAb 4E10 neutralize a wide range of different HIV-1 group M subtypes with high efficacy [4]. The MPER of gp41 was shown to be one of the most conserved regions within Env of HIV-1 [5] and therefore represents an excellent target for neutralizing antibodies. Although unsuccessful until now (for a review, see [6]), the induction of $\mathrm{mAb} 2 \mathrm{~F} 5 / 4 \mathrm{E} 10$-like neutralizing antibodies is a major goal in HIV-1 vaccine research. In contrast, neutralizing antibodies against the porcine endogenous retrovirus (PERV), the feline leukemia virus (FeLV) and the Koala retrovirus (KoRV) could be easily induced, immunizing with their TM proteins p15E [7-10]. The induced antibodies recognized two epitopes, one located in the fusion peptide proximal region (FPPR) of the N-terminal part (epitope 1, E1), and the other in the C-terminal MPER

\section{KARGER}

Fax +4161306 1234 E-Mail karger@karger.ch www.karger.com
(C) 2011 S. Karger AG, Basel 0300-5526/12/0553-0252\$38.00/0

Accessible online at: www.karger.com/int
Joachim Denner

Robert Koch Institute

Nordufer 20

DE-13353 Berlin (Germany)

Tel. +49 3018754 2800, E-Mail DennerJ@rki.de 
Table 1. Primers and probes used for the cloning of gp36 and detection of virus expression

\begin{tabular}{lll}
\hline Name & Location & Sequence $\left(5^{\prime}-3^{\prime}\right)$ \\
\hline HIV-2-RT-For & $530-548^{\mathrm{a}}$ & CTGTATAAATGTACCCGCT \\
HIV-2-RT-Rev & $721-739^{\mathrm{a}}$ & ACTTGCTTCTAATTGGCAG \\
HIV-2-RT-probe & $571-587^{\mathrm{a}}$ & FAM-CTGCGGAGAGGCTGGCA-BHQ1 \\
hGAPDH-For & $365-385^{\mathrm{b}}$ & GGCGATGCTGGCGCTGAGTAC \\
hGAPDH-Rev & $495-513^{\mathrm{b}}$ & TGGTCCACACCCATGACGA \\
hGAPDH-probe & $407-430^{\mathrm{b}}$ & HEX-TTCACCACCATGGAGAAGGCTGGG-BHQ \\
HIV-2-gp36-For & $8279-8307^{\mathrm{a}}$ & GGGACTTTCCAGAAGGGGCT \\
HIV-2-gp36-Rev & & CCAGGCGGCGACTAGGAGAG \\
His-For & $8693-8719^{\mathrm{a}}$ & TATGCATCACCATCACCATCAGG \\
His-Rev & & CGTGATGTGATGGTGATGCAT \\
\hline
\end{tabular}

FAM = 6-Carboxy-fluorescein; HEX = 5'-hexachloro-fluorescein phosphoramidite; BHQ = Black Hole Quencher.

${ }^{\mathrm{a}}$ Location refers to accession number L36874. ${ }^{\mathrm{b}}$ Location refers to accession number AF261085. ${ }^{\mathrm{c}}$ Primer comprises BamHI restriction site. ${ }^{\mathrm{d}}$ Primer comprises EcoRI restriction site and a stop-codon.

(E2) of the TM protein p15E. The location of the E2 epitopes corresponds to the location of the mAb 2F5/4E10 epitopes in gp41 of HIV-1. Despite the evolutionary distance between HIV-1 on the one hand, and PERV, FeLV as well as KoRV on the other hand, a partial sequence homology in the E2 epitope was observed (F/YEGWFN in the case of gammaretroviruses; NWFNIT, the mAb 4E10 epitope in the case of HIV-1; identical amino acids are underlined). Using ELISA, epitope mapping and surface plasmon resonance analysis it was recently shown that the presence of a peptide corresponding to the FPPR of gp41 of HIV-1 increased binding of mAb 2F5 and $\mathrm{mAb} 4 \mathrm{E} 10$ to their epitopes located in the MPER [11]. An interaction between the FPPR and the MPER of gp41 during infection has also been described [12-14]. However, immunization experiments using the recombinant ectodomain of gp41 of HIV-1 containing E1 and E2 - analogous to the successful immunization experiments using the ectodomain of gammaretroviruses - failed to induce such antibodies [unpubl. results]. To our knowledge, there is no information about $\mathrm{mAb} 2 \mathrm{~F} 5 / 4 \mathrm{E} 10$-like neutralizing antibodies in patients infected with HIV-2 and only a few attempts have been undertaken to induce such antibodies [15].

To immunize with the ectodomain of the TM protein gp36 of HIV-2, two recombinant gp36 constructs were designed. The sequence corresponding to the ectodomain of gp36 (aa511-684) was lacking the fusion peptide and the membrane-spanning domain, and was amplified by PCR from cells infected with HIV-2 ${ }_{7312 \mathrm{~A}}$ (accession No. L36874) using the primers HIV-2-gp36-For and HIV-2-gp36-Rev (table 1). The amplicon was ligated either into the expres- sion vector pCal-n (Stratagene, La Jolla, Calif., USA) or pCal-n-His using the restriction sites EcoRI and BamHI. In pCal-n-His, the CREB-binding protein (CBP) tag was removed by cleavage with the enzymes Bam HI and NdeI. Oligonucleotides comprising the sequence of a $6 x$ His-tag (His-For and His-Rev; table 1) and sticky ends for BamHI and NdeI were ligated to the CBP-deleted pCal-n. The plasmids pCal-n and pCal-n-His harboring the sequence of the ectodomain of gp36 were used for expression in the E. coli strain BL21. The recombinant protein gp36-CBP was insoluble under physiological conditions and could not be purified since the CBP tag does not allow purification under denaturing conditions. Thus, to eliminate the soluble contaminating proteins, bacteria were pelleted after expression $\left(20,000 \mathrm{~g} / 10 \mathrm{~min} / 4^{\circ}\right)$ and sonicated in $10 \mathrm{ml}$ PBS on ice (pulse: $3 \times 20$ s, break: $30 \mathrm{~s}$ with a Branson Sonifier II 250; G. Heinemann, Schwäbisch Gmünd, Germany). After collecting the insoluble gp36-CBP protein by centrifugation $\left(20,000 \mathrm{~g} / 10 \mathrm{~min} / 4^{\circ}\right)$ the resulting pellet was washed overnight with $500 \mathrm{ml}$ PBS rotating slowly at $4^{\circ}$. The next day gp36-CBP was collected again by centrifugation $\left(20,000 \mathrm{~g} / 10 \mathrm{~min} / 4^{\circ}\right)$. The protein pellet was resuspended in $10 \mathrm{ml}$ PBS and used for immunization. gp36-His was also insoluble but could be purified under denaturing conditions using $8 \mathrm{M}$ urea and Ni-NTA-agarose (Qiagen, Hilden, Germany) according the manufacturer's protocol. The purity of both proteins was analyzed by PAGE and Western blot analysis applying a cross-reacting serum from a SIVmac-infected rhesus monkey and an antipenta-His-antibody (Qiagen, Hilden, Germany; fig. 1). Female Wistar rats (Charles River, Sulzfeld, Ger- 


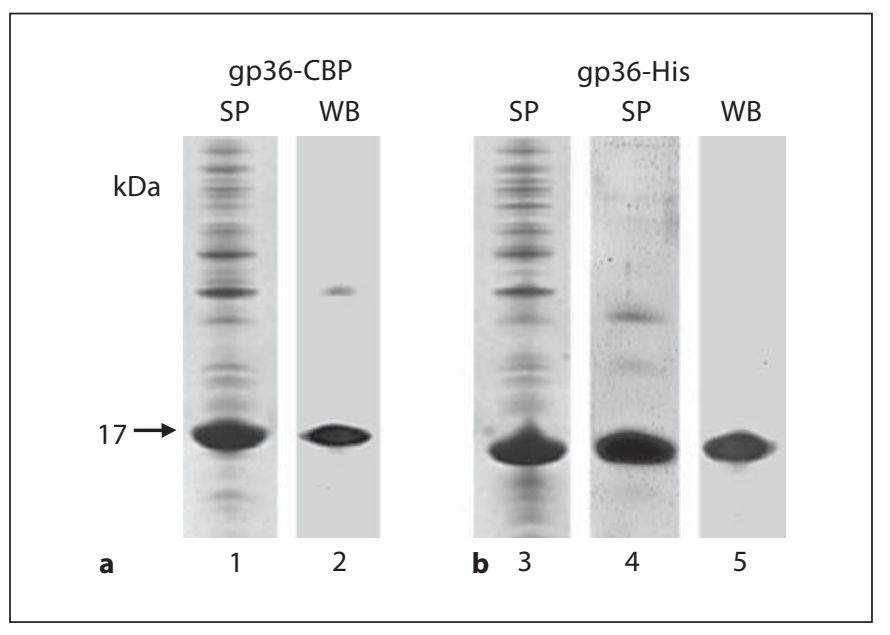

Fig. 1. SDS-PAGE (SP) and Western blot (WB) analysis using a cross-reactive serum from a SIVmac-infected animal $(1: 1,000)$ for gp36-CBP (a); an antipenta-His-antibody for gp36-His (b). Columns 1 and 2 are partially purified gp36-CBP, 3 is unpurified gp36-His, 4 and 5 are affinity-purified gp36-His.

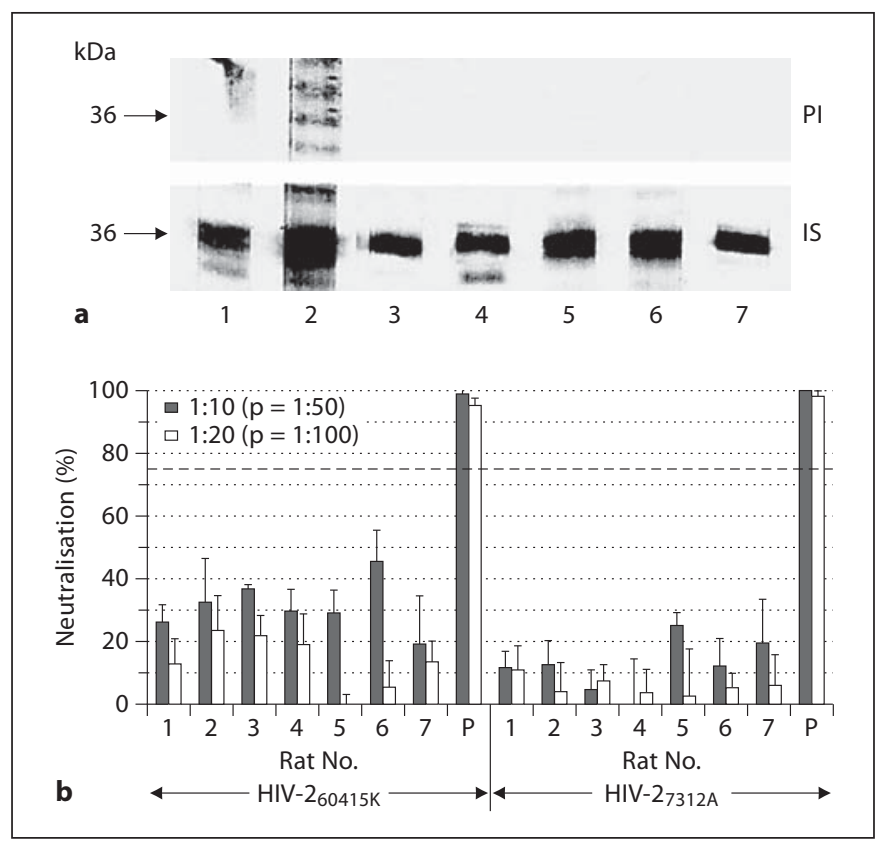

Fig. 2. Reactivity of 7 rat sera before and after immunization with gp36-CBP and gp36-His. a Western blot using a lysate of HIV$27312 \mathrm{~A}$-infected H9 cells. Sera were diluted 1:1,000, the secondary anti-rat-POD antibody was diluted 1:4,000. PI = Preimmune sera, IS = immune sera. $\mathbf{b}$ Neutralizing activity of these sera in an assay using HIV-2 ${ }_{6045 \mathrm{~K}}$ and HIV-2 ${ }_{7312 \mathrm{~A}}$. All values are means of 3 replicates with SD. All sera were diluted 1:10 and 1:20. A pool of sera (P) from 3 patients infected with HIV-2 was diluted 1:50 and 1:100 and used as a positive control. The dashed line indicates the threshold at $75 \%$ neutralization. many) were immunized twice, on day 0 and day 21 , each with $250 \mu \mathrm{g}$ of recombinant protein in $0.4 \mathrm{ml}$ PBS and 0.4 $\mathrm{ml}$ of Freund's adjuvant (Pierce, Rockford, Ill., USA). Blood samples were taken on day 35 after primary immunization and the sera were characterized by ELISA and Western blot [16]. To perform ELISA, $200 \mathrm{ng}$ of purified gp36-His were coated per well of a 96-well Nunc-Immunoplate (Nalge Nunc, Denmark) at $37^{\circ}$ overnight. Sera No. 1, 2 and 4 (gp36-CBP) showed a gp36-specific titer of 64,000; serum No. 3 (gp36-CBP) as well as No. 5 and 7 (gp36-His) of 256,000 and serum No. 6 (gp36-His) of 128,000 . Western blot analysis was performed using a lysate from H9 cells infected with HIV-2 ${ }_{7312 \mathrm{~A}}\left(\mathrm{TCID}_{50}=\right.$ $\left.10^{4.9} / 100 \mu \mathrm{l}\right)$. Cells were lysed with radioimmunoprecipitation assay buffer $(25 \mathrm{mM}$ Tris $\mathrm{HCl} \mathrm{pH} \mathrm{7.6;150} \mathrm{mM}$ $\mathrm{NaCl} ; 1 \%(\mathrm{v} / \mathrm{v}) \mathrm{NP}-40 ; 1 \%$ sodium deoxycholate; $0.1 \%$ SDS) for $30 \mathrm{~min}$ at $4^{\circ}$, and cleared by centrifugation $\left(14,000 \mathrm{~g} / 5 \mathrm{~min} / 4^{\circ}\right)$. SDS-PAGE was performed using a $14 \%$ polyacrylamide gel. All 7 sera showed a strong reaction with gp36 of HIV-2 (fig. 2a), and they were able to bind to native gp36 on H9 cells infected with HIV-2 as investigated by flow cytometry (not shown). To analyze the neutralizing activity in these sera, a newly developed assay was used, measuring neutralization as reduced provirus integration determined by real-time PCR [17]. Two HIV-2 strains were used, HIV-2 $2_{7312 \mathrm{~A}}$ (the antigen used for immunization corresponds to this virus) and HIV-2 $60415 \mathrm{~K}$, both obtained through the AIDS Research and Reference Reagent Program [18]. Briefly, after incubation of $20 \mu \mathrm{l}$ serum dilution with $80 \mu \mathrm{l}$ virus for $30 \mathrm{~min}$ at $37^{\circ}$, C8166 cells $\left(100 \mu \mathrm{l}, 5 \times 10^{5}\right.$ cells $\left./ \mathrm{ml}\right)$ were added. After $65 \mathrm{~h}$, the supernatant was aspirated and the cells were lysed by 3 freeze-thaw cycles $\left(20 \mathrm{~min}\right.$ at $-80^{\circ}$ followed by $5 \mathrm{~min}$ at $\left.60^{\circ}\right)$, followed by treatment with proteinase $\mathrm{K}(20 \mu \mathrm{g} / \mathrm{ml}$, Invitrogen) for $3 \mathrm{~h}$ at $60^{\circ}$. The enzyme was then inactivated at $95^{\circ}$ for $20 \mathrm{~min}$. The lysate was used for quantification of provirus integration by an HIV-2-specific realtime PCR, using the primers HIV-2-RT-For and HIV-2RT-Rev and the HIV-2-RT-probe (table 1). Amplification was performed using a real-time cycler MX-4000 (Stratagene, La Jolla, Calif., USA) as follows: $95^{\circ} / 10 \mathrm{~min}$ for 35 cycles: $95^{\circ} / 45 \mathrm{~s}+52^{\circ} / 60 \mathrm{~s}+72^{\circ} / 20 \mathrm{~s}$. To monitor possible toxic effects of the serum, a duplex real-time PCR was performed that simultaneously amplified the sequence in the viral LTR and a single copy sequence of glyceraldehyde-3phosphate-dehydrogenase (GAPDH) primers hGAPDHFor, hGAPDH-Rev and the hGAPDH-probe (table 1). Significant neutralization was defined as a reduction of provirus integration above $75 \%$. Neutralisation (NT) was calculated using the formula: $\mathrm{NT}=100-100 / 2^{\Delta \mathrm{Ct}}$. None 
Fig. 3. a Epitope mapping of the serum from rat 1 immunized with gp36-CBP. Three peptides (50-52) were recognized and the epitope was defined as WDVFGNWFD. $\mathbf{b}$ Sequences of the FPPR and MPER regions of gp36 of HIV-2 and schematic presentation of the epitopes recognized by sera from rats 1-7. For comparison, the corresponding sequence of gp41 from $\mathrm{HIV}-1_{\mathrm{MN}}$ (Gene Bank: M17449) is aligned. The localization of the epitopes of the monoclonal antibodies mAb 2F5 and $\mathrm{mAb}$ $4 \mathrm{E} 10$ in the $\mathrm{E} 2$ region of gp41 and of the E1 peptide No. 6342 located in the FPPR and interacting with the MPER are marked above the HIV-1 sequence. The HIV-2 sequence corresponds to isolate 7312A (Gene Bank: L36874).

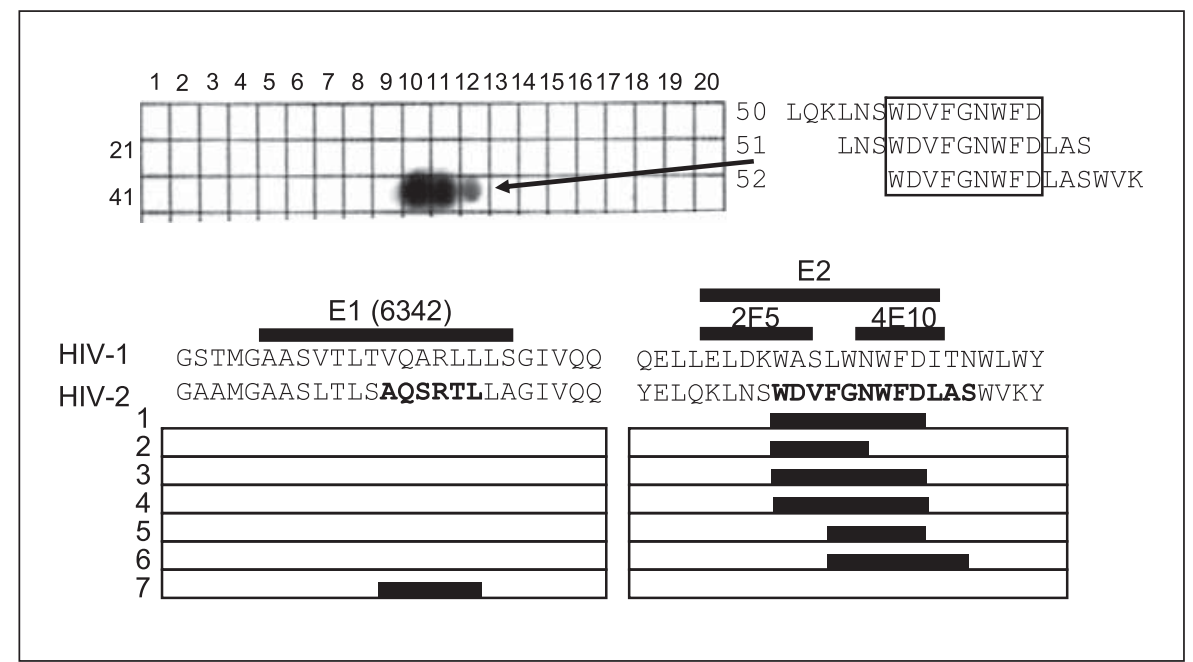

of the induced rat sera was able to reduce integration of proviruses significantly, indicating a lack of neutralizing antibodies (fig. 2b).

To map the epitopes, synthetic overlapping peptides corresponding to the ectodomain of gp 36 of HIV-2 ${ }_{7312 \mathrm{~A}}$ spotted on a membrane (JPT, Berlin, Germany) were used. Sera were diluted 1:1,000 in blocking solution (PBS $+10 \%(\mathrm{w} / \mathrm{v})$ fetal bovine serum) and incubated with the membrane for $3 \mathrm{~h}$. The membrane was washed 3 times for 15 min with Tris-buffered saline, $\mathrm{pH} 7.5$ containing $0.05 \%$ (v/v) Tween 20 (Sigma, Munich, Germany). After incubation for $2 \mathrm{~h}$ with a peroxidase-conjugated secondary antibody diluted 1:10,000 in blocking solution, binding was detected using a chemiluminescence detection solution (ECL, Amersham Biosciences, Piscataway, N.J., USA). Using this method, the epitope WDVFGNWFD, localized in the MPER of the TM protein gp36 (fig. 3), was recognized by sera from rats 1,3 and 4 . Serum from rat 2 recognized WDVFGN, serum from rat 5 recognized FGNWFD and serum from rat 6 recognized FGNWFDLAS, all located in the MPER and showing partial sequence homology to that of mAb 4E10 (NWFN/DIT) in gp41 of HIV-1 (identical amino acids are underlined). However, no cross-neutralization of HIV-1 by the sera was observed. Only one serum (rat 7) reacted with the epitope AQSRTL, localized in the FPPR, but did not react with the E2 region (fig. 3b).

Although 6 out of 7 sera reacted with a domain in the MPER of gp36 corresponding to the epitope domain of the mAb 4E10 neutralizing HIV-1 [3], and to the epitope domain of specific antibodies neutralizing the gammaretroviruses PERV [7] and FeLV [8,9] we could not ob- serve neutralization of HIV-2 by these sera. Whereas immunization with the TM proteins of PERV, FeLV and KoRV always resulted in neutralizing antibodies recognizing epitopes in the FPPR (E1) and MPER (E2), immunizations with the TM protein gp41 of HIV-1 induced neither MPER-specific nor neutralizing antibodies [unpubl. data]. A negative result was also obtained when goats and rats were immunized with the TM protein gp48 of the feline foamy virus (FFV), no antibodies neutralizing FFV were induced [19]. Potential reasons for the difference in inducing neutralizing antibodies to PERV, FeLV, and KoRV on the one hand, and HIV-1, HIV-2 and FFV on the other hand, using a similar immunization strategy, may be the following: the TM proteins of HIV-1, HIV-2 and FFV are larger and highly glycosylated whereas the TMs of gammaretroviruses are smaller and not glycosylated. Obviously, the large size, the high complexity and the strong glycosylation of the TM proteins of HIV-1, HIV-2 and FFV did not support conformations able to induce neutralizing antibodies when immunizing with the entire recombinant ectodomain. Nevertheless, broadly neutralizing antibodies such as $\mathrm{mAb} 2 \mathrm{~F} 5$ and $\mathrm{mAb} 4 \mathrm{E} 10$ have been isolated from HIV-infected individuals. This supports the view that the (glycosylated) gp41 of HIV-1 undergoes conformational changes during infection and that one of these conformations is able to induce neutralizing antibodies.

It was therefore surprising to find antibodies binding to the MPER of gp36 of HIV-2 after immunization with the recombinant ectodomain. Although immune sera raised against a linear peptide derived from the MPER of gp36 and conjugated to a carrier protein have been re- 
ported to show neutralizing activity [15], the sera obtained here did not neutralize. Until now there are no reports showing the existence and prevalence of $\mathrm{mAb}$ 2F5/4E10-like neutralizing antibodies in HIV-2-infected patients. Serum IgA from HIV-2-infected patients was described that bound to the peptide MYELQKLNSWDVFGN [20] overlapping the epitopes described here (fig. 3, WDVFGNWFGNWFDLAS, identical amino acids are underlined). This sequence contained the epitopes recognized by the sera from rats immunized with the ectodomain of gp36 (fig. 3). Although the IgA population contained neutralizing antibodies, it is unclear if the antibodies binding to the peptide were neutralizing [20]. A more detailed characterization of sequences involved in neutralization is needed. Although individuals infected with HIV-2 progress slower towards AIDS, the outcome of an HIV-2 infection is also fatal. Generating an HIV-2 vaccine would be worthwhile, especially for regions of high incidence. Based on the successful immunization experiments with the TM proteins of different gammaretroviruses, new strategies to design vaccines against HIV-1 and HIV-2 should be developed.

\section{Acknowledgments}

The following reagents were obtained from Dr. Feng Gao and Dr. Beatrice Hahn of the AIDS Research and Reference Reagent Program, Division of AIDS, NIAID, NIH: HIV-2 $2312 \mathrm{~A}$ and HIV$260415 \mathrm{~K}$.

\section{References}

1 Muster T, Steindl F, Purtscher M, Trkola A, Klima A, Himmler G, Rüker F, Katinger H: A conserved neutralizing epitope on gp41 of human immunodeficiency virus type 1 . J Virol 1993;67:6642-6647.

-2 Stiegler G, Kunert R, Purtscher M, Wolbank S, Voglauer R, Steindl F, Katinger H: A potent cross-clade neutralizing human monoclonal antibody against a novel epitope on gp41 of human immunodeficiency virus type. AIDS Res Hum Retroviruses 2001;10:1757-1765.

-3 Zwick MB, Labrijn AF, Wang M, Spenlehauer C, Saphire EO, Binley JM, Moore JP, Stiegler G, Katinger H, Burton DR, Parren PW: Broadly neutralizing antibodies targeted to the membrane-proximal external region of human immunodeficiency virus type 1 glycoprotein gp41. J Virol 2001;75:1089210905.

4 Binley JM, Wrin T, Korber B, Zwick MB, Wang M, Chappey C, Stiegler G, Kunert R, Zolla-Pazner S, Katinger H, Petropoulos CJ, Burton DR: Comprehensive cross-clade neutralization analysis of a panel of anti-human immunodeficiency virus type 1 monoclonal antibodies. J Virol 2004;78:13232-13252.

5 Gaschen B, Taylor J, Yusim K, Foley B, Gao F, Lang D, Novitsky V, Haynes B, Hahn BH, Bhattacharya T, Korber B: Diversity considerations in $\mathrm{HIV}-1$ vaccine selection. Science 2002;296:2354-2360.

-6 Montero M, van Houten NE, Wang X, Scott JK: The membrane-proximal external region of the human immunodeficiency virus type 1 envelope: dominant site of antibody neutralization and target for vaccine design. Microbiol Mol Biol Rev 2008;72:54-84.
Fiebig U, Stephan O, Kurth R, Denner J: Neutralizing antibodies against conserved domains of p15E of porcine endogenous retroviruses: basis for a vaccine for xenotransplantation? Virology 2003;307:406-413.

$>8$ Langhammer S, Fiebig U, Kurth R, Denner J: Neutralising antibodies against the transmembrane protein of feline leukaemia virus (FeLV). Vaccine 2005;23:3341-3348.

-9 Langhammer S, Hubner J, Kurth R, Denner $\mathrm{J}$ : Antibodies neutralizing feline leukaemia virus (FeLV) in cats immunized with the transmembrane envelope protein p15E. Immunology 2006;117:229-237.

-10 Fiebig U, Hartmann MG, Bannert N, Kurth $\mathrm{R}$, Denner J: Transspecies transmission of the endogenous koala retrovirus. J Virol 2006;80:5651-5654.

-11 Fiebig U, Schmolke M, Eschricht M, Kurth $\mathrm{R}$, Denner J: Mode of interaction between the HIV-1-neutralizing monoclonal antibody 2F5 and its epitope. AIDS 2009;23:887-895.

12 Noah E, Biron Z, Naider F, Arshava B, Anglister J: The membrane proximal external region of the HIV-1 envelope glycoprotein gp41 contributes to the stabilization of the six-helix bundle formed with a matching $\mathrm{N}^{\prime}$ peptide. Biochemistry 2008;47:6782-6792.

13 Bellamy-McIntyre AK, Lay CS, Baar S, Maerz AL, Talbo GH, Drummer HE, Poumbourios P: Functional links between the fusion peptide-proximal polar segment and membrane-proximal region of human immunodeficiency virus gp41 in distinct phases of membrane fusion. J Biol Chem 2007; 282:23104-23116.

14 Buzon V, Natrajan G, Schibli D, Campelo F, Kozlov MM, Weissenhorn W: Crystal structure of HIV-1 gp41 including both fusion peptide and membrane proximal external regions. PLoS Pathog 2010;6:e1000880.
15 Skott P, Achour A, Norin M, Thorstensson R, Bjorling E: Characterization of neutralizing sites in the second variable and fourth variable region in gp125 and a conserved region in gp36 of human immunodeficiency virus type. Viral Immunol 1999;373:72-84.

16 Tacke SJ, Bodusch K, Berg A, Denner J: Sensitive and specific immunological detection methods for porcine endogenous retroviruses applicable to experimental and clinical xenotransplantation. Xenotransplantation 2001;8:125-135.

$>17$ Behrendt R, Fiebig U, Norley S, Gurtler L, Kurth R, Denner J: A neutralization assay for HIV-2 based on measurement of provirus integration by duplex real-time PCR. J Virol Methods 2009;159:40-46.

- 18 Gao F, Yue L, Robertson DL, Hill SC, Hui H, Biggar RJ, Neequaye AE, Whelan TM, Ho DD, Shaw GM: Genetic diversity of human immunodeficiency virus type 2: evidence for distinct sequence subtypes with differences in virus biology. J Virol 1994;68:7433-7447.

19 Mühle M, Bleiholder A, Kolb S, Hübner J, Löchelt M, Denner J: Immunological properties of the transmembrane envelope protein of the feline foamy virus and its use for serological screening. Virology 2011, Feb 10 [Epub ahead of print].

20 Lizeng Q, Skott P, Sourial S, Nilsson C, Andersson S S, Ehnlund M, Taveira N, Björling E: Serum immunoglobulin A (IgA)-mediated immunity in human immunodeficiency virus type 2 (HIV-2) infection. Virology 2003;308:225-232. 